PACS: $61.50 . \mathrm{Ah}, 64.10 .+\mathrm{h}$

\title{
THERMODYNAMICS AND STRUCTURAL CONDITION OF PB-SB ALLOYS
}

\author{
N.Yu. Filonenko \\ State Establishment "Dnipropetrovsk Medical Academy of Health Ministry of Ukraine” \\ Vladimir Vernadsky Str., 9, Dnipro, 49044, Ukraine \\ e-mail: natph2016@gmail.com \\ Received 9 December, 2017
}

In this paper we study the structural condition and thermodynamic functions of a melt of the Pb-Sb. The investigations were performed for alloys with an antimony content of 5.0-20.0\% (wt.), the rest is lead. To determine the structural condition of alloys we use microstructure analysis, differential thermal and X-ray structural analyses. The phase composition of alloys was determined in relation to the temperature of the liquid heating above the liquidus curve and to the cooling rate. With accounting for the first degree approximation of high-temperature expansion of the thermodynamic potential in expression for the Gibbs energy of a melt of the binary $\mathrm{Pb}-\mathrm{Sb}$ alloy we find the curve of thermodynamic stability of the liquid depending on the antimony content in alloy. This approach enables to give the most complete description of the alloys' melt from the thermodynamic point of view and to determine a thermodynamic stability curve, above which there are no microcomplexes in the phase. The results of the calculations obtained in this paper are in good agreement with the experimental data.

KEY WORDS: Pb-Sb alloys, free energy of the phase, melt, thermodynamic stability

\section{ТЕРМОДИНАМІКА ТА СТРУКТУРНИЙ СТАН СПЛАВІВ СИСТЕМИ Рb-Sb Н.Ю. Філоненко \\ Д3 «Дніпропетровська державна медична академія МОз Украӥни» 49044, Украӥна, м. Дніпро, вул. Володимира Вернадського, 9}

У роботі досліджено структурний стан та отримані термодинамічні функції розплаву $\mathrm{Pb}-\mathrm{Sb}$. Дослідження проводили на сплавах з вмістом сурми 5,0-20,0\% (мас.), решта свинець. Для визначення структурного стану сплавів використовували мікроструктурний, рентгеноструктурний та диференційний термічний аналізи. Було визначено фазовий склад сплавів в залежності від температури нагріву розплаву вище лінії ліквідусу та швидкості охолодження. 3 врахуванням внеску наближення першого ступеня високотемпературного розвинення термодинамічного потенціалу в виразі для енергії Гіббса рідини бінарного сплаву $\mathrm{Pb}-\mathrm{Sb}$ отримано лінію термодинамічної стійкості розплаву в залежності від вмісту сурми в сплаві. Використаний у даній роботі підхід дає можливість надати найбільш повний з термодинамічної точки зору опис розплаву сплавів та визначити лінію термодинамічної стійкості, вище якої в фазі відсутні будь-які мікрокомплекси. Отримані результати розрахунків добре узгоджуються з експериментальними даними.

КЛЮЧОВІ СЛОВА: сплави $\mathrm{Pb}-\mathrm{Sb}$, енергія Гіббса, розплав, термодинамічна стійкість

\section{ТЕРМОДИНАМИКА И СТРУКТУРНОЕ СОСТОЯНИЕ СПЛАВОВ СИСТЕМЫ Pb-Sb Н.Ю. Филоненко}

ГУ «Днепропетровская государственная медииинская академия МОЗ Украины»» 49044, Украина, г. Днепр, ул. Владимира Вернадского, 9

В работе исследованы структурное состояние и получены термодинамические функции расплавов $\mathrm{Pb}-\mathrm{Sb}$. Исследования проводились на сплавах с содержанием сурьмы 5,0-20,0\% (мас.), остальное - свинец. Для определения структурного состояния использовали микроструктурный, рентгеноструктурный и дифференциальный термический анализы. Был определен фазовый состав сплавов после охлаждения до комнатной температуры в зависимости от температуры нагрева расплава выше линии ликвидуса и скорости охлаждения. С учетом вклада приближения первой степени высокотемпературного разложения термодинамического потенциала в выражении для энергии Гиббса бинарного расплава $\mathrm{Pb}-\mathrm{Sb}$ получена линия термодинамической устойчивости расплава в зависимости от содержания сурьмы в сплаве. Использованный в данной работе подход позволяет предоставить наиболее полное с термодинамической точки зрения описание плавления сплавов и определить линию термодинамической устойчивости, выше которой в расплаве отсутствуют какие-либо микрокомплексы. Полученные в работе результаты расчетов хорошо согласуются с экспериментальными данными.

КЛЮЧЕВЫЕ СЛОВА: сплавы $\mathrm{Pb}-\mathrm{Sb}$, энергия Гиббса, расплав, термодинамическая устойчивость

Сплави системи $\mathrm{Pb}-\mathrm{Sb}$ відносяться до діаграм першого типу, в яких обмежена розчинність у твердому стані та не утворюють хімічних сполук [1]. Як відомо, у сплавах $\mathrm{Pb}-\mathrm{Sb}$ при вмісті сурми 13,1 \% (мас.) та температурі $\mathrm{Te}=(525,3 \pm 0,5) \mathrm{K}$ відбувається утворення евтектики $\mathrm{L}=\mathrm{Pb}+\mathrm{Sb}$ [2-4].

Наразі відомо, що при температурах, що перевищують температуру кристалізації в розплавах металів та сплавів спостерігали мікроконцентраційну неоднорідність [5-6]. Як відомо, одним із методів визначення наявності мікрокомплексів в розплаві є визначення в'язкості розплаву [7]. Проведені дослідження залежності в'язкості сплавів $\mathrm{Pb}-\mathrm{Sb}$ від температури показали, що при збільшенні температури в'язкість сплавів зменшується [8-10], що пов'язують зі зменшенням або відсутністю в розплаві сплавів утворення мікрокомплексів.

Таким чином, явища, які спостерігали в рідкому стані металів та сплавів притаманні для систем, які 
знаходяться в критичному стані [11]. Для таких систем характерна наявність температури при якій відсутні будь-які комплекси в розплаві.

Як відомо, швидкість охолодження впливає на процес кристалізації сплавів. За результатами впливу швидкого охолодження сплавів системи $\mathrm{Pb}-\mathrm{Sb}$ до температури 83 К були виявлені нові фази, які включають в себе ОЦК (W-A2-типу) та примітивну кубічну фазу скоординованої (можливо, типу NaCl-B1) [12]. Bплив швидкого охолодження на сплави розглянуто в роботі [13], в якій, зокрема, зазначено, що перехолодження сурми досягає $\Delta \mathrm{T}=408 \mathrm{~K}$, а свинцю $\Delta \mathrm{T}=353 \mathrm{~K}$, а в роботі [7] вказано, що для сурми відносне переохолодження $\Delta \mathrm{T}=279 \mathrm{~K}$, а свинцю $\Delta \mathrm{T}>474 \mathrm{~K}$.

Таким чином, метою даної роботи було дослідити структурний стан сплавів $\mathrm{Pb}-\mathrm{Sb}$ в залежності від температури нагріву сплаву вище лінії ліквідусу, швидкості охолодження, а також визначити границю однорідного та неоднорідного розплаву.

\section{МАТЕРІАЛИ ТА МЕТОДИКА ДОСЛІДЖЕНЬ}

Дослідження проводили на зразках із вмістом сурми 5,0-20,0 \% (мас.), решта свинець. Для отримання яких використовували шихту такого складу: свинець з вмістом 99,9 \% (мас.) та сурму з вмістом 99,9 \% (мас.). Для попередження ліквації сплави виготовляли із заздалегідь ретельно перемішаних і спресованих порошків матеріалів шихти. Виплавку зразків проводили при температурах 520-900 К в печі Тамана 3 графітовим нагрівачем. Швидкість охолодження сплавів складала $10 \mathrm{~K} / \mathrm{c}$. Частину зразків виготовляли таким же методом, але після нагріву виливали в клиновидні форми, за рахунок чого при охолодженні в широкій частині клина була отримана швидкість охолодження $10^{2} \mathrm{~K} / \mathrm{c}$, в середній $10^{3} \mathrm{~K} / \mathrm{c}$, а в тонкій $10^{4} \mathrm{~K} / \mathrm{c}$.

Для визначення хімічного складу сплаву використовували хімічний та спектральний аналіз [14]. Для визначення температури фазових перетворень використали термічний аналіз на «Деревотографі» зі швидкістю нагріву $2 \mathrm{~K} \cdot \mathrm{xB}^{-1}$. Фазовий склад сплавів після охолодження визначали методом мікрорентгеноспектрального аналізу на мікроскопі JSM-6490, а також за допомогою оптичного мікроскопу «Неофот-21». Рентгеноструктурний аналіз здійснювали на дифрактометрі ДРОН-3 в монохроматизованому Со випромінюванні.

\section{РЕЗУЛЬТАТИ ТА ЇХ ОБГОВОРЕННЯ}

Доевтектичні сплави мають наступну структуру: первинні дендрити та не регулярна евтектика свинцю та сурми, заевтектичні - первинні кристали сурми та евтектика.

Морфологія евтектики в сплавах системи $\mathrm{Pb}-\mathrm{Sb}$ має майже регулярну структуру (рис. 1a). За результатами диференційного термічного аналізів температура утворення евтектики складала 523 К при вмісті сурми 13,0 \% (мас.) (рис. 1б).

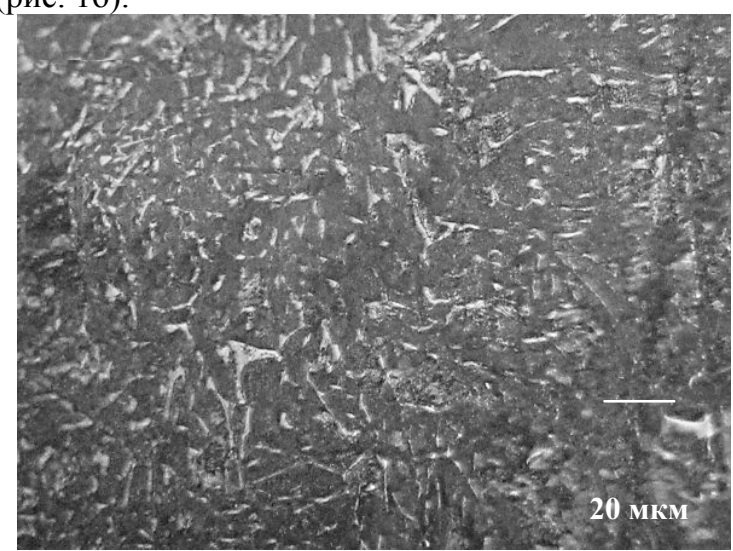

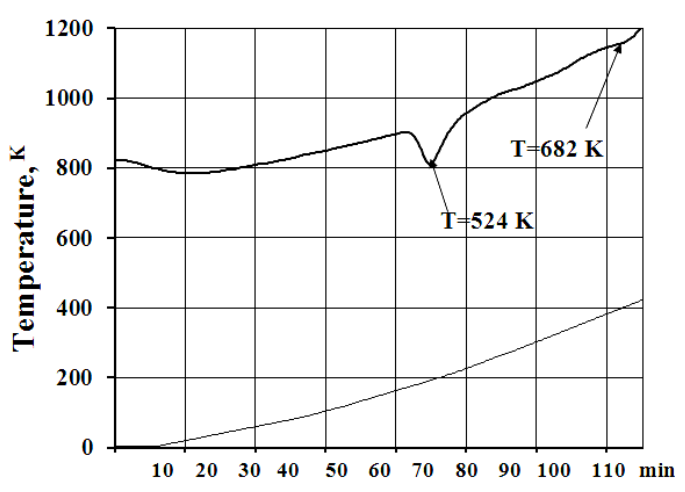

б

Рис. 1. Сплав $\mathrm{Pb}-\mathrm{Sb} 3$ вмістом сурми 13,0 \% (мас.)

a - мікроструктура після охолодження, б - крива диференційного термічного аналізу

На кривій диференційного термічного аналізу спостерігали в інтервалі температур 680-700 К у розплаві евтектичного сплаву незначний тепловий ефект, який свідчить про зміну структури рідини. Для визначення впливу нагріву вище лінії ліквідусу на формування структури сплавів охолоджених 3 різними швидкостями зразки сплавів Pb-Sb нагрівали до температури на 520-900 К та виливали в клиновидні форми. Нагрів розплаву вище лінії ліквідусу до 150 К як доевтектичних, евтектичних, так і заевтектичних сплавів не призвів до значної зміни структурних складових та їх морфології.

В доевтектичному сплаві (вміст сурми 11,2 \% (мас.), який був нагрітий вище лінії ліквідусу на 200 К спостерігали формування первинних кристалів свинцю в матриці з евтектикою. При швидкості охолодження сплавів $10^{2} \mathrm{~K} / \mathrm{c}$ відбувається формування кристалів свинцю (12-20 мкм) та збільшення їх об’ємної частки у 
порівнянні з зразками 3 таким же вмістом сурми, які охолоджені з більшими швидкостями охолодження (рис. 2а). Збільшення швидкості охолодження до $10^{3} \mathrm{~K} / \mathrm{c}$ призводить до формування більш неоднорідних за розміром первинних кристалів свинцю (7-10 мкм). Евтектика має більш дисперсну структуру в порівнянні 3 зразками, які були охолоджені з меншою швидкістю.

Зміну морфології евтектики від пластинчастої до дрібнодисперсної стержневої спостерігали в ділянці клина охолодженої зі швидкістю $10^{4} \mathrm{~K} / \mathrm{c}$ та значне зменшення об'ємної частки первинних кристалів свинцю (рис. 2б).

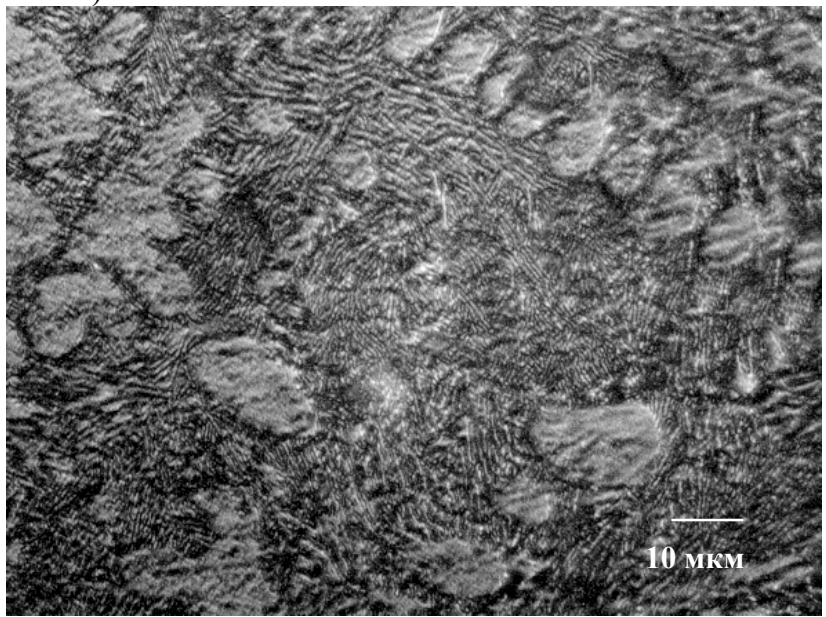

a

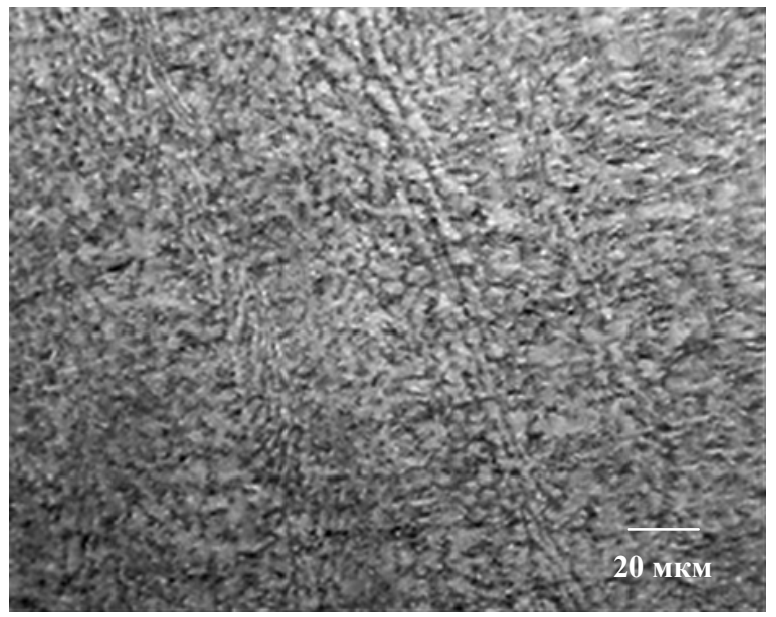

б

Рис. 2. Мікроструктура сплаву $\mathrm{Pb}-\mathrm{Sb}$ з вмістом сурми $11,2 \%$ (мас.)

a - швидкість охолодження $10^{2} \mathrm{~K} / \mathrm{c} \times 500,6$ - швидкість охолодження $10^{4} \mathrm{~K} / \mathrm{c} \times 1000$

Після охолодження зі швидкістю $10^{2} \mathrm{~K} / \mathrm{c}$ товстої частини клина заевтектичного сплаву (3 вмістом $15 \%$ (мас.) сурми) спостерігали виділення первинних кристалів сурми в евтектиці, яка має нерегулярну морфологію (рис.3а). Мікроструктура тонкої частини клина охолодженого зі швидкістю $10^{4}$ К/с представлена дрібнодисперсною сумішшю свинцю та сурми (рис. 3б). Виділення первинних кристалів сурми в даній частині клина не спостерігали.

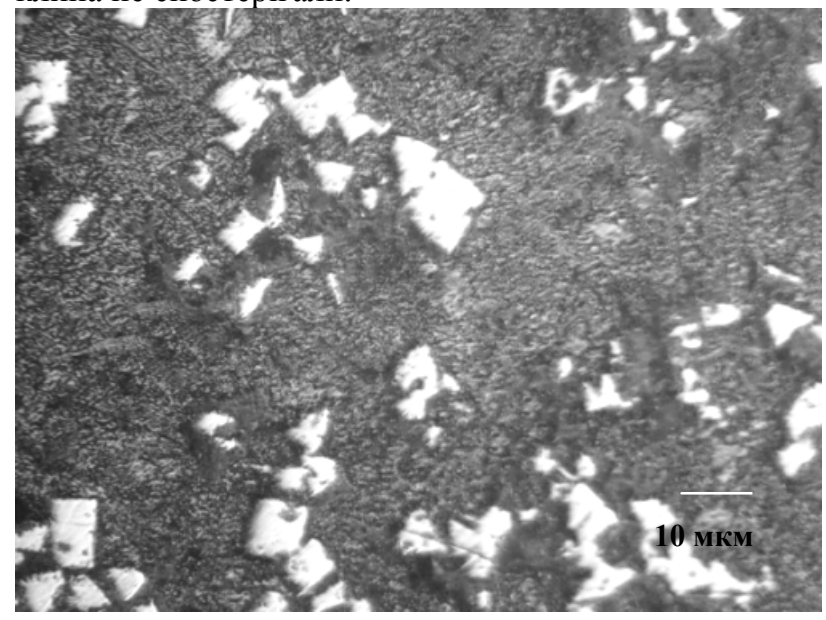

a

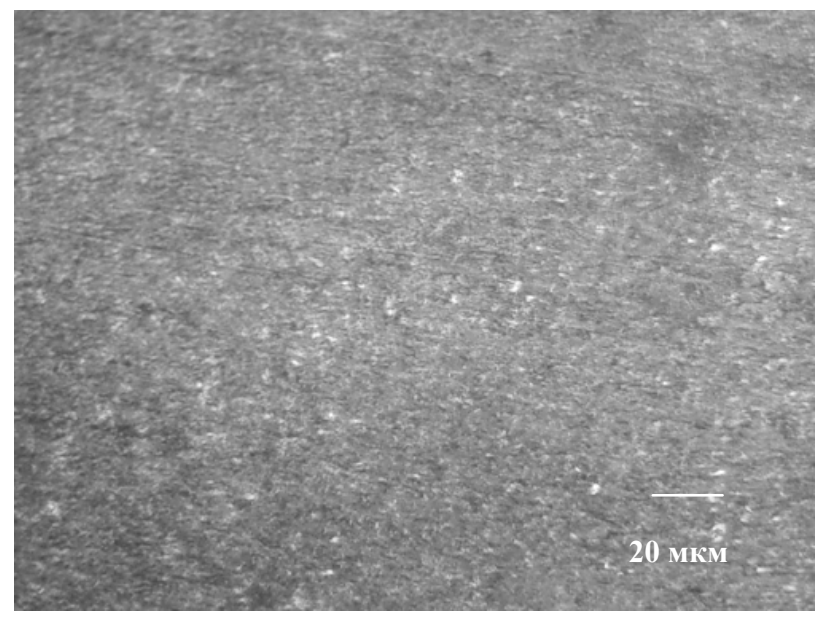

6

Рис. 3. Мікроструктура сплаву $\mathrm{Pb}-\mathrm{Sb} 3$ вмістом сурми 15,0 \% (мас.) $\mathrm{a}$ - швидкість охолодження $10^{2} \mathrm{~K} / \mathrm{c}, 6$ - швидкість охолодження $10^{4} \mathrm{~K} / \mathrm{c}$

Результати рентгенофазового аналізу сплавів показали, що в доевтектичному сплаві $\mathrm{Pb}-\mathrm{Sb}$ при вмісті сурми 11,2\% (мас.) відбувається незначний зсув на лініях дифракторгами в бік менших кутів, а в заевтектичному сплаві при вмісті сурми 15,0 \% (мас.) не спостерігали зміщення та змінення інтенсивності ліній дифрактограми (рис. 4).

Таким чином, при підвищенні температури перегріву сплавів вище лінії ліквідусу на 200 К та послідуючому охолодженні відбувається утворення дрібнодисперсної евтектики та значне зменшення об'ємної частки первинних кристалів.

Для визначення впливу температури нагріву розплаву на формування структури сплаву можна застосувати розрахунковий метод. Як відомо, для того, щоб система знаходилась в стані термодинамічної стійкої рівноваги, треба щоб D (детермінант стійкості системи) та коефіцієнти головної діагоналі були позитивні [16]. 


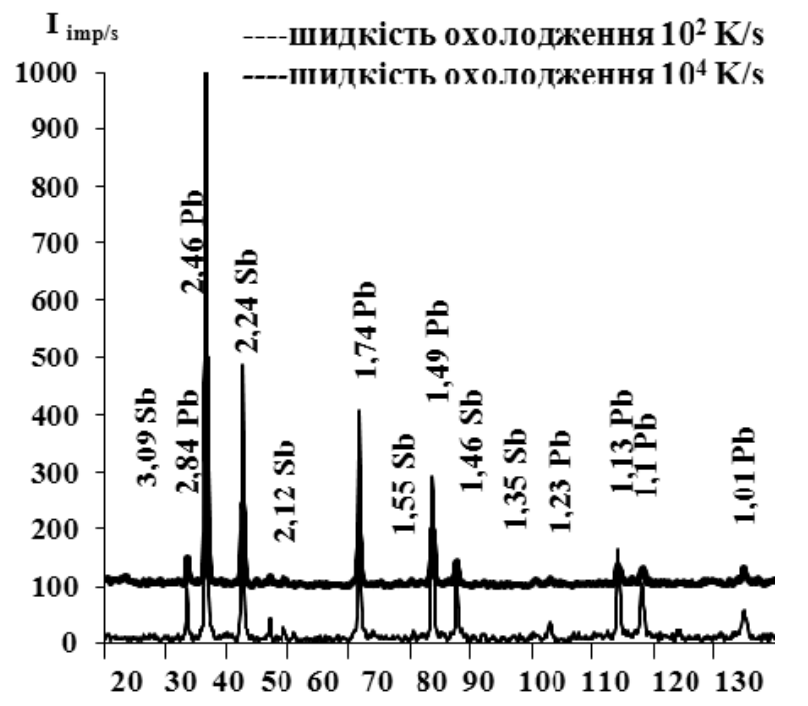

a

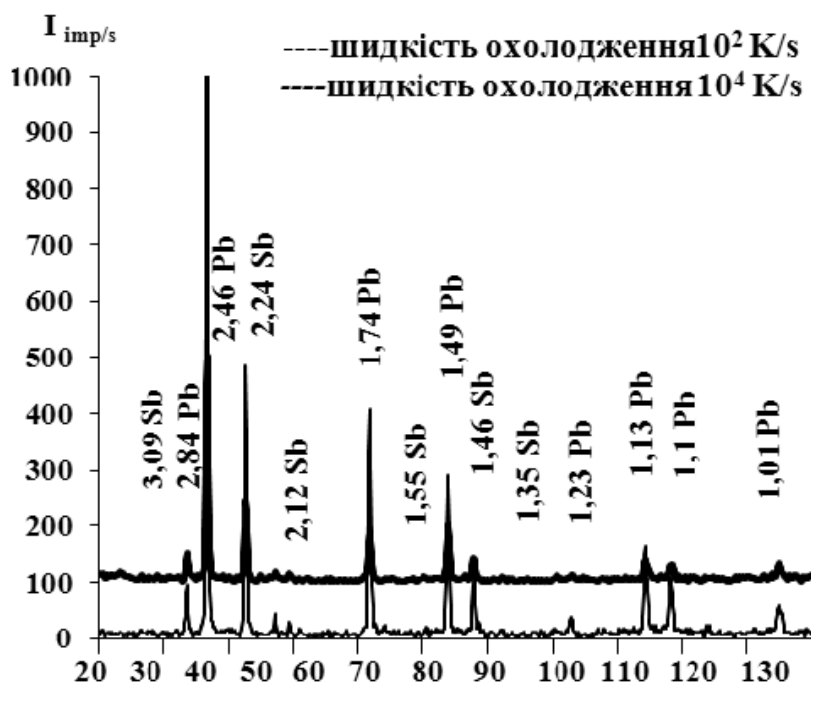

б

Рис. 4. Дифрактограма сплавів
a- вміст сурми $11,2 \%$ (мас.), б - вміст сурми $15,0 \%$ (мас.)

Випадок, коли $\mathrm{D}=0$ був вперше зазначений Гіббсом, як критичний стан речовини [16]. При закритичних переходах детермінант і коефіцієнти стійкості проходять через скінченні мінімуми, які відповідають розвитку флуктуацій. Граничним випадком, який є критичним станом, коли флуктуації в системі досягають максимальних значень, детермінант стійкості і коефіцієнти стійкості проходять через мінімуми, які дорівнюють нулю. Для визначення цих значень розглянемо умову, при якій $\mathrm{dD}=0$.

При розрахунку термодинамічних функцій фаз для високотемпературної області врахували внесок першого ступеня наближення високотемпературного розвинення термодинамічного потенціалу бінарного сплаву у вигляді нескінченного ряду за ступенями $1 /$ T [17].

Енергію Гіббса з урахуванням наближення першого ступеня для розплаву $\mathrm{Pb}-\mathrm{Sb}$ визначимо як:

$$
G_{m}=x_{1} G_{1}^{0}+x_{2} G_{2}^{0}+R T\left(x_{1} \ln x_{1}+x_{2} \ln x_{2}\right)+x_{1} x_{2} L_{12}-\frac{L_{12}^{2} x_{1}^{2} x_{2}^{2}}{2 Z T R},
$$

де $\mathrm{x}$ - масовий вміст елементів. Для мольних часток компонентів в сполуці чи сплаві виконується умова $\sum_{i=1}^{2} x_{i}=1$. Використовуючи дані для чистих компонент ${ }^{0} G_{P b},{ }^{0} G_{S b}$ [18-19], а дані енергії взаємодії між компонентами в фазі $L_{P b: S b}$ з робіт [2-3], були отримані залежності енергії Гіббса розплаву від температури.

Детермінант стійкості розплаву з урахуванням (1) має вигляд:

$$
D=\left|\begin{array}{ccc}
\frac{L_{12}^{2} x_{1}^{2} x_{2}^{2}}{Z R T^{3}} & R\left(\ln x_{2}+1\right)+\frac{L_{12}^{2} x_{1}^{2} x_{2}}{Z R T^{2} 2} & R\left(\ln x_{1}+1\right)+\frac{L_{12}^{2} x_{1} x_{2}^{2}}{Z R T^{2}} \\
R\left(\ln x_{2}+1\right)+\frac{L_{12}^{2} x_{1}^{2} x_{2}}{Z R T^{2}} & \frac{R T}{x_{2}}-\frac{L_{12}^{2} x_{1}^{2}}{Z R T} & \frac{-2 L_{12}^{2} x_{1} x_{2}}{Z R T} \\
R\left(\ln x_{1}+1\right)+\frac{L_{12}^{2} x_{1} x_{2}^{2}}{Z R T^{2}} & \frac{-2 L_{12}^{2} x_{1} x_{2}}{Z R T} & \frac{R T}{x_{1}}-\frac{L_{12}^{2} x_{2}^{2}}{Z R T}
\end{array}\right|
$$

Для визначення стійкості повинна виконуватись умова $d D=0$.

Умова виконується, коли

$$
d D=\left(\frac{\partial D}{\partial T}\right)_{x} d T+\left(\frac{\partial D}{\partial x_{1}}\right)_{T} d x_{1}+\left(\frac{\partial D}{\partial x_{2}}\right)_{T} d x_{2}=0 .
$$

$$
\left(\frac{\partial D}{\partial T}\right)_{x}=0,\left(\frac{\partial D}{\partial x_{1}}\right)_{T}=0 \quad\left(\frac{\partial D}{\partial x_{2}}\right)_{T}=0 .
$$

Результат розв'язку системи (2) представлений на рис. 5.

Таким чином, за результатами вище приведених розрахунків для отримання однорідної розплаву $\mathrm{Pb}-\mathrm{Sb}$, яка не містить мікроділянок з ближнім порядком, необхідно виконати перегрів на 170-250 К в залежності від вмісту сурми в сплаві, що корелює з експериментальними даними (рис. 5). 


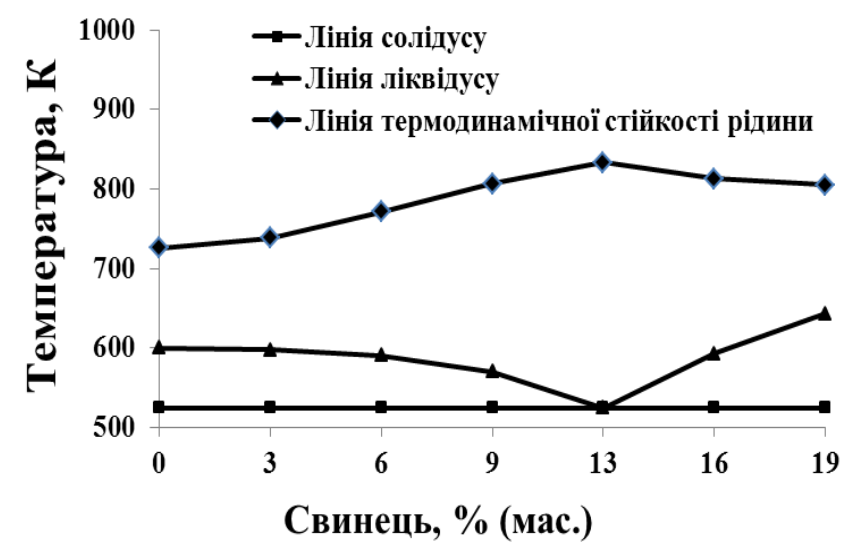

Рис. 5. Лінія термодинамічної стійкості на діаграмі стану системи $\mathrm{Pb}-\mathrm{Sb}$

Аналіз отриманих результатів показав, що нагрів розплаву Pb-Sb вище від лінії ліквідусу на $170-250$ K призводить до зменшення об'ємної частки первинних кристалів свинцю при кристалізації для доевтектичного сплаву, а в заевтектичному сплаві об'ємної частки первинних кристалів сурми. При швидкостях охолодження $10^{4} \mathrm{~K} / \mathrm{c}$ відбувається утворення дрібнодисперсної евтектики та пригнічення процесу формування первинних кристалів.

\section{ВИСНОВКИ}

1. Температура нагріву розплаву та швидкість охолодження впливає на розмір та об'ємну частку первинних кристалів для сплавів доевтектичного, евтектичного та заевтектичного складу.

2. У сплавах системи $\mathrm{Pb}-\mathrm{Sb}$ не залежно від температури нагріву та вмісту сурми не відбулося змін фазового складу. Перегрів розплаву на температуру вище 170-250 К та при послідуючому охолодженні призводить до утворення дрібнодисперсної евтектичної структури та пригнічення процесу формування первинних кристалів свинцю та сурми у порівнянні зі зразками, які мали меншу температуру перегріву.

3. Результати розрахунку з урахуванням внеску наближення першого ступеня високотемпературного розвинення термодинамічного потенціалу бінарного сплаву дали змогу отримати лінію термодинамічної стійкості плавлення сплавів системи $\mathrm{Pb}-\mathrm{Sb}$ та дозволили визначити температурний інтервал при якому в розплаві відсутні мікрокомплекси, а також дали можливість прогнозувати кінцеву структуру сплаву.

\section{СПИСОК ЛИТЕРАТУРИ}

1. Lyakishev N.P. Diagrammy sostoyaniya dvoinykh metallicheskikh sistem:Spravochnik [Phase Diagrams of Binary Metal Systems:Handbook]. Vol. 3, book 1. - Moscow: Mashinostroenie, 2001. - 498 p.

2. Hassama S., Boab D., Fouquea Y., Kotchib K.P., Roge J. Thermodynamic investigation of the Pb-Sb system // Journal of Alloys and Compounds. - 2009. - Vol.476. - P.74-78.

3. Ashtakala, Pelton A.D., Bale C.W The Pb-Sb (Lead-Antimony) // System Bulletin of Alloy Phase Diagrams. - 1981. Vol.2(1). - P. 86-89.

4. Abdel-Reihim, Hess N., Reif W., Birch M.E.J. Effect of solute content on the grain refinement of binary alloys // Journal of Materials science. - 1987. - No. 22. - P. 213-218.

5. Taran Yu.N., Mazur V.I. Struktura evtekticheskih splavov [Structure of eutectic alloys]. - Moscow: Metallurgiya, 1978. $312 \mathrm{p}$.

6. Zhukova L.A., Popel S.I. Elektronograficheskoe issledovanie stroeniya rasplavov [Electrographic study of the structure of melts] // Journal of Physical Chemistry. - 1982. - Vol. 56(11). - P. 2702-2706.

7. Somov A.I., Tihonovskiy M.A. Evtekticheskie kompozitsii [Eutectic compositions]. - Moscow: Metallurgiya, 1975. - 287 p.

8. Crawley A.F. The viscosities of some lead-antimony and lead-antimony-tinalloys // Physics and Chemistry of Liquids: A International Journal. - 1970. - Vol.2(2). -P. 77-85.

9. $\quad$ Pola A., Gelfi M., Modegell M., Roberti R. Semisolid lead-antimony alloys for cars batteries // Trans. Nonferrous Met. Soc. China. - 2010. - Vol. 20. - P. 1774-1779.

10. Morioka S., Xiufang Bian, Minhua Sun A model of viscosity for liquid metals // Z. Metallkunde. - 2002. - Bd 93(4). P. 288-292.

11. Kalashnikov E.V. Termodinamicheski neustoychivyie sostoyaniya v evtekticheskih sistemah [Thermodynamic unstable state in thermodynamic systems] // Journal of Technical Physics. - 1997. -Vol. 67(4). - P. 7-12.

12. Claude Borromee-Gautier, Giesen Bill C., Nicholas Grant J. Metastable Phases in the Pb-Sb and Pb-Bi Systems // Journal of chemical physics. - 1968. - Vol.48(5). - P. 1905-1911.

13. Perepezko J.H. Solidification of highly supercooled liquid metals and alloys // Journal of Non-Crystalline Solids. - 1993. P. 463-472.

14. Tverdokhlebova S.V. Spectrometry of the boron-containing alloys // Visnyk Dnipropetrovskogo nacionalnogo universitetu. 
Serija.fizika. Radioelektronika. - 2007. - Vol. 14(12/1). - P. 100-104.

15. Syichev V.V. Differentsialnyie uravneniya termodinamiki [Differential equations of thermodynamics]. - Moscow: Vyisshaya shkola, 1991. - $220 \mathrm{p}$.

16. Gibbs Dzh.V. Termodinamicheskie rabotyi [Thermodynamics work]. - Moscow: Gosteh izdat, $1950-320 \mathrm{p}$

17. Zhirifalko L. Statisticheskaya fizika tverdogo tela [Statistical Solid State Physics]. - Moscow: Mir, 1975. - 376 p.

18. Roble R.A., Waldbaum D.R. Thermodynamic Properties of Minerals and Related Substances at $298.15^{\circ} \mathrm{K}\left(25.0^{\circ} \mathrm{C}\right)$ and $\mathrm{One}$ Atmosphere (1.013 Bars) Pressure and at Higher Temperatures Orton memorial library the OHIO State University 155 S. Oval Drive, 1970. - P. 262.

19. SGTE data for pure elements A T Dinsdale NPL Materials Centre, Division of Industry and Innovation, National Physical Laboratory, Teddington, Middlesex, TW11 0LW, UK. - 174 p. 